\title{
AUTHOR
}

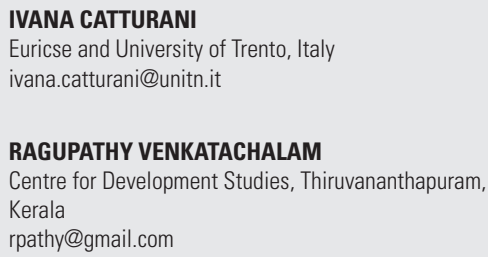

\section{Optimal Interest Rates in \\ Cooperative Banks with Non-member Customers}

\section{ABSTRACT}

Previous attempts to understand the functioning of cooperative banks have often considered them as being similar to credit unions. However, we argue that credit unions are only a subset of cooperative financial institutions and the models used to describe their behavior cannot be generalized to all cooperative banks. Additionally, there is an important factor that characterizes cooperative banks' behavior and outcomes, which does not apply to credit unions: the role of nonmembers and their contribution to the members' overall welfare through bank deposits and interest earnings. In this paper, we move from the Smith et al. (1981) model developed to describe credit unions' pricing policy on interest rates and we propose a more general model by incorporating nonmember depositors and borrowers, who play a key role in determining cooperative banks' interest rates.

\section{KEY-WORDS}

OPTIMAL INTEREST RATES; COOPERATIVE BANKS; CREDIT UNIONS

\section{Acknowledgements}

The authors are very grateful to Silvio Goglio and Yiorgos Alexopoulos for their insightful comments.

JEL Classification: D210; G21 | DOI: http://dx.doi.org/10.5947/jeod.2014.009 


\section{Introduction}

The literature has widely discussed the role of cooperative banks ${ }^{1}(\mathrm{CBs})$ in local development, as well as their contribution in mobilizing local savings and expanding access to credit to both households and small businesses (Petersen, 1995; Berger et al., 1999; DeYoung et al., 1999; Bonaccorsi di Patti and Gobbi, 2001; Goglio, 2009). It is pivotal to better understand how these institutions function, as well as the associated outcomes, in order to then study their impact on the economic and banking system. CBs can be viewed as financial intermediaries whose stated main goal is to increase their members' welfare and whose owners (the members) do not always receive dividends from their shares ${ }^{2}$. According to these facts, it is rather obvious that CBs cannot be generically classified as "for-profit" banks; hence, they are usually treated as "not-for-profit" banks. However, "not-for-profit" banks are a heterogeneous group of institutions. Various types of not-for-profit banks include: mutual saving banks, mutual savings and credit unions in the United States (US), building societies and credit unions in the United Kingdom (UK), and cooperative banks in Europe, such as Raiffeisen and Volksbank. Among not-for-profit banks, the most common types are cooperative banks (including in this case also Banche Popolari and Volksbank) and credit unions.

Since these banks are not profit-driven, understanding and precisely defining their objectives for the purposes of theoretical investigation becomes an interesting and challenging task. In this paper, we attempt to describe how cooperative banks manage to provide privileges to its members, who form the bank's ownership structure. In particular, we are interested in understanding the magnitude of member benefits received for deposits or loans, compared to non-members. These member benefits include preferential treatment through favorable interest rates both on loans and deposits. In this paper, we restrict our focus to the monetary aspects of member benefits, which include preferential treatment through both better terms and favorable interest rates on loans as well as deposits. However, non-monetary social benefits can be appropriately introduced into this framework, if so desired.

Unlike cooperative banks, which are recognized as banks, credit unions are more challenging to define. According to the Oxford Dictionary of Economics (2009), a bank is defined as a financial institution whose main activities are borrowing and lending money. Does this properly define credit unions? As defined by Berthoud and Hinton (1989), credit unions are "cooperative societies that offer loans to their members out of the pool of savings that are built up by members". By being suppliers of loans and collectors of deposits, credit unions can be considered financial institutions, yet not actually banks. Accordingly, the US Federal Reserve defines credit unions as depository institutions, not banks, thus does not supervise or regulate them.

Contrarily in the UK, the Prudential Regulation Authority regulates credit unions. However, the bank of England clearly states that credit unions are not the same as banks. According to its definition expressed

\footnotetext{
In this paper, the expression "cooperative banks" is used interchangeably with and as shorthand of "cooperative financial institutions". In the case of Italy, Germany and Austria, Banche di Credito Cooperativo and Raiffeisen are usually included in the broader set of cooperative banks. Dissimilarly, given the difference in the dividends redistribution policy and the fact of not being subject to mutuality requirements (at least in the Italian case), Banche Popolari as well as Volksbanks are not considered into the cooperative banks group, at least for the purpose of this paper.

2 As an example, in the case of Italian Banche di Credito Cooperativo (BCCs), the Italian Civil Code Art. 2514 establishes that BCCs cannot distribute dividends on the subscribed capital superior to the maximum interest of postal bonds increased by 2.5 per cent. This limit regards "dividends." Moreover, these cooperatives cannot distribute reserves to user-members and in case of dissolution; they shall return all their assets to the mutual funds for the promotion and the development of cooperation (Fici, 2010).
} 
by Muqtadir (2013), credit unions are "mutual societies that are run as financial cooperatives. They are community based organizations [...] set up for the benefit of a particular group or community that share a common bond. This common bond might be living or working in certain area, belonging to a particular organization, or working for a certain employer". Figure 1 attempts to graphically capture the discussion above.

Figure 1. The financial organizations frame

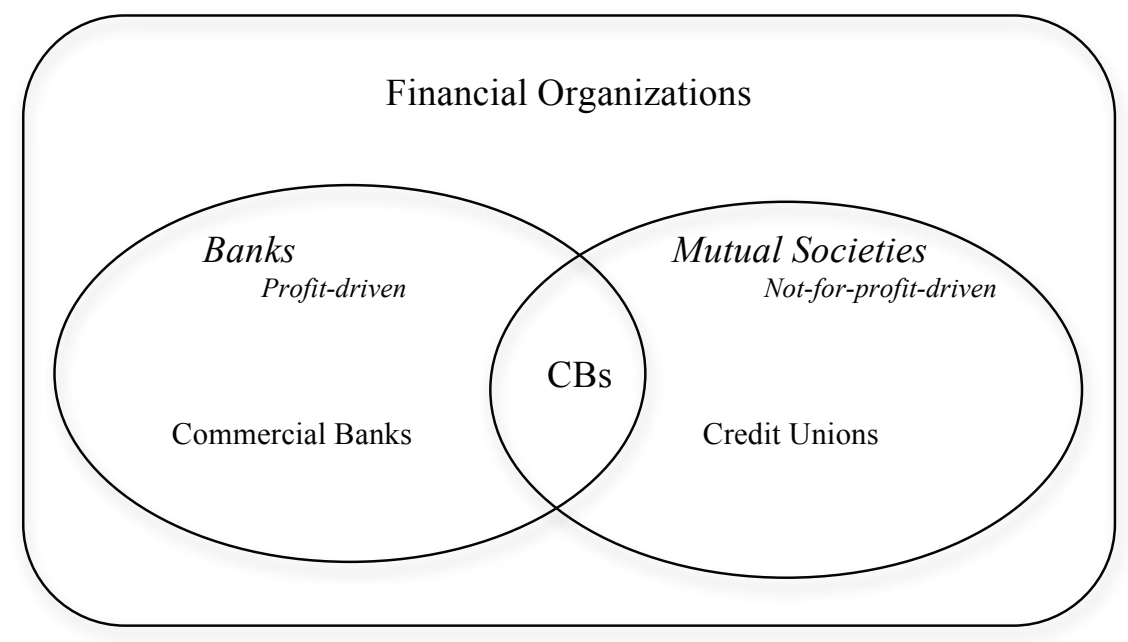

Given that their business is strictly catered only to members, credit unions can be viewed as a special case of cooperative financial institutions - one without non-member customers. The absence of non-member customers could reduce the agency problem ${ }^{3}$; in terms of modeling, it simplifies the bank's objective function. In contrast, cooperative banks usually include non-member customers in addition to its members. The differing characteristics of these two bank types imply that we cannot analyze and understand their activities through using a restrict model. In this paper, we attempt to modify a model of credit union behavior by generalizing it so as to incorporate additional characteristics that are specific to CBs. We are interested in understanding the problem of interest rate determination while preferential member treatment is present. This is important because the presence of non-member customers introduces new complexities in the optimal problem setting to define members' privileges. Non-members indirectly contribute to financing members' privileges since, at least in theory, they pay relatively higher interest rates on loans compared to members. They also provide the bank with deposits. Higher shares of non-members result in more resources for members. CBs not only have to deal with the member-to-non-member antagonism, but also with the internal battle of benefit distribution between borrowers and depositors.

The extent to which members forgo the option of taking more loans instead of receiving better privileges would depend on their own demand for loans. In our framework, the amount of loans borrowed will determine each member's preference for either a borrower- or depositor-oriented policy on interest rates. It is the CB's responsibility to set appropriate interest rates on loans and deposits in order to be incentive compatible and to distribute the available resources between the two groups of members (borrowers and depositors). In order to do so, we need to consider three different relationships, paired with their motivations:

3 Referring to Figure 1, in Alexopoulos et al. (2013) the absence of non-members will reduce the number of principals controlling both the board of directors and the manager and will mitigate the agency problem. 
1. Customers vs. non-customers: The decision of the customers to approach cooperative banks, rather than financial intermediaries, is often motivated by financial conditions (for simplicity we consider the case of better interest rates) for both loans and deposits ${ }^{4}$.

2. Members vs. non-members: Among customers, members need to be repaid for their role in the ownership of the CB. This is typically in terms of better interest rates and not through dividend payments, in lines with their "not-for-profit" motive.

3. Borrowers vs. Depositors: Among members, the distribution of the welfare gains between the two categories (borrowers and depositors) also matters. The eventual magnitudes of privilege (i.e., terms for loans and deposits) will depend on which member category forms the majority.

There are models describing how credit unions set their interest rates to compensate members (Smith et al., 1981; Emmons and Mueller, 1998; Emmons and Schimd, 2002). To the best of our knowledge, general models describing the activities of all types of cooperative banks are not available. In this paper, we attempt to develop a baseline normative model, which can be extended to incorporate additional features. The questions that we try to address are: What are the optimal interest rates (for loans and deposits) for a welfare-maximizing cooperative bank that privileges its members, and on what do they depend? Second, how do these interest rates change according to the distribution of members (i.e. whether borrowers or depositors represent the majority group)?

The paper is organized as followed: Section 2 surveys the relevant literature, in particular, those comparing cooperative banks and credit unions. Section 3 presents some broad empirical patterns regarding the pattern of member shares across countries. Section 4 defines the theoretical model, then Section 5 comments on the main findings. Section 6 closes through further discussion and suggesting possible extensions of the model.

\section{Cooperative banks and credit unions: A literature review}

In order to address the questions concerning the pricing decision of CBs, it is important to understand their peculiarities and specific goals. As noted in Smith et al. (1981, p. 519), two characteristics distinguish credit unions from other types of banks: (i) the members are simultaneously bank owners, customers of the outputs and suppliers of the inputs, and (ii) both the demand and the supply sides are transacted within the same enterprises, since the bank includes both member-borrowers and member-depositors. These characteristics could be applied to CBs as well when dealing solely with members. Given their ownership structure, CBs cannot be considered profit maximizers. Pantaleoni (1898; 1924) raised the issue concerning cooperative enterprises' aim by arguing that cooperatives were not charitable institutions, but instead driven by their members' selfish expectations. Member welfare lies at the core of cooperative actions. According to standard microeconomic theory, under perfect competition, cooperatives will not be able to maximize consumer and producer surplus since they do not explicitly focus on profit maximization.

4 There might be other reasons as well, such as the absence of alternative options to borrow in the nearby area, low penetration of commercial banks, etc. Even in this case, these geographical constraints would mean an increase in transaction costs (and opportunity costs) for the customer, thus should be added while comparing various banks' costs and benefits. For simplicity, we assume that the customer's decision is motivated purely by interest rate differences in the presence of substitute options. 
Focusing on banks with a cooperative ownership structure, some authors have interpreted them as cost-minimizing enterprises (Taylor, 1977), similarly to public/state enterprises. However, this vision does not take into consideration their cooperative aim. The objective of $\mathrm{CBs}$ is to benefit their members, in line with their cooperative principles. The benefits accruing to the CBs' owners are not restricted to solely financial gains; CBs maximize the members' so-called wealth rather than just profits. Social factors, local development and human capital can be included in the CB's objective function. Members benefit from the public good created by CBs: the availability of a financial service. However, non-members can benefit from the availability of this public good as well, behaving as free riders.

CBs redistribute their profits through price subsidies - i.e., through lower interest rates on loans or higher interest on deposits (Hart and Moore, 1998). On the one hand, this may be seen as distorting the invisible hand in the market by distorting prices, but on the other hand, it helps CBs realize their stated objective.

However, given that the amount of resources to be redistributed is limited, a potential conflict among members can arise. This is particularly so since borrowers and depositors have not only different, but often opposing concerns. Therefore individual utility may be at the cost of another's. Even though both types of members (borrowers and depositors) may gain from better interest rates compared to non-members, there is a potential internal conflict concerning the benefit allocation. The conflict resolution is based on the prevalence of one type of member over the other (Smith et al., 1981; Emmons and Schimd, 2002). When members are asked to vote in the general assembly, if the median voter shifts from borrower to depositor, the resulting benefit redistribution choice could change accordingly. Thus, the choice between keeping low interest on loans or raising the price of credit depends on the composition of the majority in the assembly (Emmons and Mueller, 1997). The decisions regarding the allocation of the surplus can ultimately be related with the interest rates charged on loans and deposits (Emmons and Schimd, 2002). While analyzing German CBs, Emmons and Mueller (1997) show that a shift in the median member from being predominantly borrower-oriented towards being predominantly lender-orientated causes a corresponding shift in the cooperative banks pricing policy. In this case, it moved from having underpriced credit towards the provision of competitively priced credit and deposit services.

While the internal quarrel between borrowers and depositors remains in the case of credit unions, the discrimination of interest rates between members and non-members disappears. This is because, in contrast to cooperative banks, credit unions do not serve non-members. According to Croteau (1963), credit unions are the purest form of cooperative financial institutions for two reasons: (i) they restrict transactions to members only, and (ii) the membership is constrained to those belonging to a common bond. Credit unions collect deposits solely from members and lend only to members. Users, management and beneficiaries are only found among credit unions' members (Ward and McKillop, 1997). In this sense, credit unions can be considered as a subset of cooperative banks, whose customers are also always members. The restriction to a common bond is a fundamental point for these banks' success, since it implies reciprocal knowledge and moral persuasion in the case of opportunistic behavior.

In the literature, the theoretical framework for credit unions setting interest rates has been well developed (Smith et al., 1981; Smith, 1984, 1988). Contrarily, other forms of cooperative banks have received less attention; in particular, studies emphasizing the influence of members and non-members are extremely rare. 


\section{Member-to-customer ratio patterns}

Focusing on broad descriptive statistics concerning CBs across the world, it is possible to realize how much situations can vary. On the one hand, $\mathrm{CBs}$ are largely present in Europe, even though it is also possible to find a large number in Canada and Japan. In Europe, CBs play an important role in the economic and financial system. There are almost 4,000 European CBs with 71,000 branches and more than 200 million customers, mainly consumers, communities and small and medium-sized enterprises (SMEs) (EACB, 2013). Among customers, more than 50 million are members, while 180 million are non-members 5 . CBs around the world show substantial differences in terms of their spatial characteristics and lending models. In some countries, such as Italy, CBs have remained small and local with an internal decision board of directors; in others, as in the case of the Netherlands, CBs are integrated in a vertical structure, where the decisional autonomy of each bank is very restricted.

Credit unions, on the other hand, are mainly located in the Anglo-Saxon world. At the end of 2012, there were almost 53,000 credit unions spread over 101 countries around the world, with more than 200 million members. The countries with the most credit union activity are highly diverse. They range from the US, with the highest number of members at 92 million and possessing a 45.4 per cent penetration share, to Canada with a share of 43.7 per cent penetration, to others, such as Kenya (penetration share equal to 19.5\%), South Korea (16.5\%), Mexico (4.9\%), Brazil (3.4\%) and India (2.5\%) (see footnote 5).

Focusing on CBs, the "member-to-customer ratio" greatly varies among European countries. Data collected for the CBs Federation bodies show that while the Dutch Rabobank has roughly 71,000 customers per bank, the German DZ has around 23,000 customers. The ratio is more than five-to-one in the first case, while it falls to two-to-one in the second case. In Austria, the Raiffeisen group is nowadays owned by circa 1.7 billion members, who represent 20 per cent of the population in 2013. The share of customers is slightly higher, reaching 43 per cent. Focusing on data collected at the single bank level and comparing Austrian figures in 2004 and 2009, the ratio fell and the number of non-member customers grew faster than that of members, while in Germany the opposite happened. In the case of Italy, the ratio was decreasing at least until 2007, whereas it started increasing again after 2009. Finally, it has to be noted that in some countries such as Belgium and Ireland, CBs count only members as customers, as in the case of credit unions. On the contrary, Slovenia and Luxemburg show the lowest member-to-customer ratios among European countries, as seen in Table 1.

\footnotetext{
5 Although it would be helpful to draw a more precise frame of the phenomenon described by including data on the proportion of members vs. non-members, both for borrower and depositors, this paper does not have the ambition of describing real optimal rate decisions. It instead aims to define an abstract model that gives some hints as to the determinants of various interest rates.
} 
Table 1. European CBs member- to-non-member ratios

\begin{tabular}{|c|c|c|c|c|c|c|c|c|c|}
\hline & 2004 & 2005 & 2006 & 2007 & 2008 & 2009 & 2010 & 2011 & $\begin{array}{c}\text { Average } \\
\text { per } \\
\text { country } \\
\end{array}$ \\
\hline Austria & 69,4 & 69,4 & 45,5 & 67,0 & 66,5 & 66,5 & 67,5 & 48,0 & 63,4 \\
\hline Belgium & & & 100,0 & & & & & & 100,0 \\
\hline Bulgaria & 1,2 & 0,9 & 0,8 & 1,0 & & 63,0 & & & 13,4 \\
\hline Cyprus & 0,1 & 0,1 & 89,2 & & 50,0 & 86,0 & & & 45,1 \\
\hline Denmark & 56,1 & 52,5 & 52,5 & & & 53,0 & 50,0 & & 48,5 \\
\hline Germany & 51,7 & 52,4 & 53,3 & 54,0 & 54,0 & 55,0 & & & 53,4 \\
\hline Spain & 17,4 & 18,5 & 19,4 & 19,0 & 20,0 & 21,0 & & & 19,2 \\
\hline Finland & 35,6 & 36,5 & & 33,5 & 30,0 & 31,0 & 31,0 & 40,0 & 33,9 \\
\hline France & 38,9 & 38,9 & 37,2 & 45,3 & 47,3 & 54,0 & 50,5 & 71,0 & 45,2 \\
\hline Greece & 100,0 & 100,0 & 100,0 & & & & & 54,0 & 88,5 \\
\hline Hungary & 50,0 & 50,0 & 25,0 & 23,0 & 14,0 & 11,0 & 11,0 & & 26,3 \\
\hline Ireland & 100,0 & & & & & & & & 100,0 \\
\hline Italy & 31,8 & 33,2 & 14,8 & 14,0 & & 15,0 & 19,0 & & 21,5 \\
\hline Japan & & & & 19,0 & 19,0 & & & & 19,0 \\
\hline Lithuania & 99,0 & 99,2 & 99,2 & 99,0 & & 99,0 & & 100,0 & 99,2 \\
\hline Luxemburg & 3,9 & 3,8 & 4,6 & 5,0 & & 5,0 & 6,0 & & 4,7 \\
\hline Netherland & 16,2 & 17,2 & 18,2 & 18,0 & & 23,0 & & & 18,5 \\
\hline Poland & 23,8 & 23,8 & 23,8 & 24,0 & & & & & 23,9 \\
\hline Portugal & 18,8 & 25,0 & 33,3 & 15,0 & 25,0 & 35,0 & & 34,0 & 26,6 \\
\hline Romania & 100,0 & 75,5 & 68,8 & & & & & & 81,5 \\
\hline Slovenia & & & 0,1 & & & & & & 0,1 \\
\hline Sweden & 100,0 & 100,0 & 83,2 & & & & & & 94,4 \\
\hline Switzerland & 62,5 & 45,2 & 45,7 & & & & & & 51,1 \\
\hline $\begin{array}{l}\text { United } \\
\text { Kingdom }\end{array}$ & & & & 50,0 & 25,0 & 38,0 & 39,0 & 46,0 & 39,6 \\
\hline $\begin{array}{l}\text { Average per } \\
\text { year }\end{array}$ & 48,1 & 44,5 & 42,9 & 34,6 & 39,4 & 46,9 & 44,7 & 61,6 & 46,5 \\
\hline
\end{tabular}

Source: EACB, key statistics, various years

Note: Ratios are presented in percentage values

\section{A framework for assessing $\mathrm{CB}$ member benefits}

A commonly recognized core objective for $\mathrm{CBs}$ is to improve member wealth through offering more favorable financial conditions. However, the challenge is to translate this formally into an objective function, as done in conventional microeconomics. This exercise turns out to be a bit more complex than usual and it involves three dimensions that ought to be considered. 


\subsection{Customers vs. non-customers}

First, the $\mathrm{CB}$ s need to be competitive in the market for long-run survival. In order to attract customers, the interest rates offered by $\mathrm{CBs}$ should be more favorable than those offered by commercial banks. That is, an economizing borrower or depositor will decide to become a CB customer if he receives at least the same, if not better, financial conditions than the outside option offers (e.g. other commercial banks) ${ }^{6}$. Thus, in order to be competitive, the best strategy is to offer better financial conditions than competitors. However, some customers might not have an outside option at all, or the search and access costs associated with these options may not be zero. It is such for instance in small villages, where the local $\mathrm{CB}$ is the only existent financial institution. In order to evaluate the profitability of the CB's offer, the interest rate in this case would need to be considered as a composite term to capture these costs as well. In this paper, we assume that the outside option is available, since these mentioned considerations are not central to our story.

\subsection{Members vs. non-members}

The second dimension is the guarantee that preferential treatment will be given to members (our model translates special treatment into more profitable interest rates for members, acknowledging that other incentives can also play a role). On the one hand, from a purely risk point of view, even though the members are less-profitable ${ }^{7}$, they are more secure given the lower asymmetry of information regarding the CB's lending risks. On the other hand, non-member customers are charged higher interest rates on loans and lower interest rates on deposits compared to members. They are more profitable but less safe, given that the CBs have less information about their risks when compared to members ${ }^{8}$. Therefore CBs ought to set interest rates for non-members that will enable them to be competitive in the market while at the same time attract enough profitable customers. The profit can be used to reward members in terms of better financial conditions. Moreover, non-members should not be indiscriminately considered as a riskier group, since soft information may sometimes be available even in their case. Given the differential terms provided for non-members, all else (including risk) being equal, it is possible to view members as "rent-seekers" who extrapolate value from "others".

Given this, the proportion between members and non-members in the total customer pool becomes strategically important choices made by the CBs, particularly those concerning interest rates. This is so because members gain from the CB's lending activities to non-member customers, who pay higher interest rates on loans. These gains are not redistributed as profits, but translate into better terms for members. In some cases, the proportion of financial activities addressed to members and to non-members is given by

6 For customers moved by altruistic behavior, offering the same conditions as competitors is enough since they would receive benefits through a not-for-profit organization in se.

7 This is strictly from the perspective of CBs as a profit-oriented entity. They are less profitable since they pay lower interest rates than other customers and receive better terms on deposits. They receive a compensation for their participation in the risky capital of the CB, while the capital invested is a small amount.

8 This pertains largely to the soft information regarding the risks that are involved. CBs often operate on the strength of being able to collect soft information regarding their members. Here we consider non-members to be from outside the member community and on whom soft information is not readily available. Nowadays it is also difficult to collect soft information on members for various reasons, such as softer community links, larger membership and privacy laws. However, ceteris paribus, members can still be considered less risky since they are also CB owners. 
existing norms ${ }^{9}$. The most extreme case is credit unions.

In order to become members, the customers should receive incentives of better financial conditions, especially on loans. According to this, one would reason that even a minor improvement or gain, net of entry costs, should push customers to apply for membership. However, according to the data shown above, being a member may not always be appealing or possible. The reason for this counterintuitive evidence could be that customers are not always eligible to become members according to national rules (for instance, in Italy the customer must live within the CB's reference area to be eligible). It seems that these non-member customers still prefer to be a customer of a CB rather than move to a commercial bank. This could be partly because CBs provide better terms on loans and deposits as compared to other outside options, even for non-members. Another prominent factor may relate to aspects such as the CB's spatial proximity, familiarity and effective marketing.

\subsection{Borrowers vs. depositors}

The third dimension is related to the nature of the financial relationship that members have with their CB. A member, in principle, can be both a borrower and a depositor. The relative bargaining power of these groups within CBs depends on the number of members of each type - i.e., the majority of either borrowers or depositors, since decision-making follows the "one-head, one-vote" rule. As pointed out by Emmons and Schimd (2002), the goals of these two groups are often opposing. CBs redistribute benefits to members mainly through preferential interest rate policies. The borrowers get benefits via a reduction in the interest on loans, which in turn will cause a reduction in the CB's earnings. The depositors ask for benefits through an increase in the interest rates on deposits, which in turn increase banking costs. The reduction in bank earnings could lead to a reduction in the interest rate paid to depositors as well. An increase in the interest rates paid on deposits would increase the expenditures and could result in higher interest rates on loans.

CBs' management (or the relevant decision-making body - i.e. the board of directors) have to decide which of the two groups will receive relatively more benefits for their membership. They have some discretion when it comes to deciding whether to increase the interest rates on members deposits (rewarding depositors), or to reduce the interest rates on loans (rewarding borrowers). Since members express their power by voting in the general assembly, the directors will end up favoring the group that corresponds to the majority of votes. If the majority is satisfied with the management's proposal regarding benefit redistribution ${ }^{10}$, it will implicitly approve them through the approval of the annual balance sheet.

In order to describe the possible preferential choices made by CBs, Smith (1984) suggests an interesting framework. Even though this model was originally developed for credit unions, it can be generalized to also describe the issues that CBs encounter. In this setup, the CB's objective would be to maximize the value for members and hence, it can be translated into a straightforward constrained maximization problem. The main difference between this model and that of credit unions is the role of non-members along with the borrower-depositor distinction among members.

We can now continue to set up the model. The model's aim is to see how optimal interest rates, both

9 In the Italian case, it is not possible to open a new branch if the minimum member threshold (at least 200) is not available in the proposed area. Moreover, according to the mutuality requirements, at least 50 per cent of the CB's risky activities, such as loans, should be addressed to their members to be eligible for tax reductions.

10 We implicitly assume that the members, individually and as a group, act in favor of their own benefit; therefore, altruistic concerns are not taken into account here. Given the "cooperative" aim, this could be a limitation of our proposed model. However, even though the organization is driven by a cooperative aim, members are not necessarily driven by the same goal. 
for loans and deposits, vary for member and non-member customers taking into account the members' distributional composition. This is a baseline model and we have therefore considered a situation in which there is no uncertainty in order to keep the analysis simple. The generalizations, though cumbersome, are relatively straightforward.

\section{Model setup}

The first step in constructing this would be to understand the financial gains that members accrue through their participation in a CB. Members' Gain from Loans (NGL) and Gain from Deposits (NGD) need to be understood before we investigate the optimal interest rates associated with loans and deposits.

\subsection{Loans}

Let the total size of the amount loaned be $L$, out of which $\alpha \mathrm{L}$ is the share of the total loans going to members and $(1-\alpha) L$ is the share of total loans going to non-members.

$L=\alpha L+(1-\alpha) L=L_{M}+L_{N M}$

Let $\mathrm{rM}$ be the interest rate on the loan for the members while rNM represents the interest rate charged for the non-members. The rate at which the $\mathrm{CB}$ can borrow from other banks is $\mathrm{rB}$. Lastly, let $\mathrm{rO}$ be the outside option for members and non-members ( $\mathrm{rO}-r_{N M} r_{N M}$ is the gap that allows CBs to attract customers from competitors). The following ordering of the rates is needed to align incentives for being a member, where $\mathrm{rO}$ and $\mathrm{rB}$ are exogenously determined:

$r_{B}<r_{M}<r_{N M} \leq r_{O}$

We assume the loan demand schedules for both groups to be:

$L_{M}=\vartheta\left(r_{O}-r_{M}\right)$

$L_{N M}=\omega\left(r_{O}-r_{N M}\right)$

\subsection{Deposits}

Assume that the members' total size of deposits is $\beta D$ and that $(1-\beta) D$ be the share of non-member deposits out of the total deposits held by the CB.

$D=\beta D+(1-\beta) L=D_{M}+D_{N M}$

Let $\mathrm{iM}$ be the rate of return on the deposits for the members, $\mathrm{iNM}$, be the non-member rate, $\mathrm{iB}$, the rate at which the $\mathrm{CB}$ can borrow from other banks and $\mathrm{iO}$ be the outside option for the members and non-members ( $i_{N M}-\mathrm{iO}$ is the gap that allows $\mathrm{CBs}$ to attract customers from competitors). Aligning with the cooperatives aim to give priority to members, the different rates of return on deposits have to satisfy the 
following, where $\mathrm{iO}$ is exogenously given ${ }^{11}$ :

$i_{M}>i_{N M} \geq i_{O}$

We assume the following supply schedules for members and non-members:

$D_{M}=\mu\left(i_{M}-i_{O}\right)$

$D_{N M}=\varphi\left(i_{N M}-i_{O}\right)$

\subsection{Objective function}

The CB's objective is taken to be the maximization of the welfare of its members. We do not focus on the members' non-pecuniary welfare at this point; however, it could always be included if required. The members' monetary gains arise from two different channels: (i) the gains from preferential interest rates on loans for members, and (ii) the gains from better returns on the deposits for members compared to other banks. Net Gain from Loans (NGL) and Net Gain from the Deposits (NGD) can be formulated as follows:

$$
\begin{aligned}
& N G L=\left(r_{O}-r_{M}\right) L_{M}+\left(r_{N M}-r_{M}\right) L_{N M} \\
& N G D=\left(i_{M}-i_{O}\right) D_{M}+\left(i_{M}-i_{N M}\right) D_{N M}
\end{aligned}
$$

The CB's objective can be viewed as a task of finding the optimal interest rates for loans and rates of return for deposits for both members and non-members, so as to maximize the member's welfare. After simplifying it a bit, the objective function can be written as:

$$
\begin{aligned}
& \max _{r_{M}, r_{N M}, i_{M}, i_{N M}} N G L+N G D \\
& \max _{r_{M}, r_{N M}, i_{M}, i_{N M}} L_{M}\left(r_{O}-r_{M}\right)+L_{N M}\left(r_{N M}-r_{M}\right)+D_{M}\left(i_{M}-i_{O}\right)+D_{N M}\left(i_{M}-i_{N M}\right)
\end{aligned}
$$

We also add the composition factor underlying the member structure - whether the majority of the members are borrowers or depositors. We can weigh the members' net gains from loans and deposits with the parameter capturing the average preference towards each of these two categories. This parameter, $\gamma$, will take the value one if the board of the cooperative has a complete borrower majority while $\gamma=1 / 2$ will imply that the board is neutral between the interests of these two categories. The modified objective function will now be:

$\max _{r_{M}, r_{N M}, i_{M}, i_{N M}} \gamma\left[L_{M}\left(r_{O}-r_{M}\right)+L_{N M}\left(r_{N M}-r_{M}\right)\right]+(1-\gamma)\left[D_{M}\left(i_{M}-i_{O}\right)+D_{N M}\left(i_{M}-i_{N M}\right)\right.$

The implicit assumption is that deposits and loans essentially mature after one period. However, this is not the case in reality, since the loans and deposits have different maturity periods across customers. We can

11 While the interbank lending rate, $\mathrm{rB}$, is an important boundary for the definition of the interest rate on loans (e.g. Eurirs or Euribor), the same is not true for $\mathrm{iB}$, the corresponding rate on deposits. For this reason, we do not include $\mathrm{iB}$ as a boundary in our model. 
modify this structure, as in Smith (1984), to introduce parameters that capture the proportions of loans and deposits that are retired during each period, $\theta, \mathrm{T}$ as well as discount rates $\delta$. Assuming that a constant proportion, $\theta$, of the loans are retired every period, the balances would also decline every period. While calculating the present value of net gains in a given period for members' loans, one would need to account for the future stream mentioned above. It should be appropriately discounted for each period by a factor, $\delta$, which we assume to be constant. The same applies for deposits. The objective function is to maximize the present value of the net gains from loans and deposits for its members. This can be written as:

$$
\begin{aligned}
\max _{r_{M}, r_{N M}, i_{M}, i_{N M}} \gamma\left(\frac{1+\delta}{\delta+\theta}\right)\left[L_{M}\left(r_{O}-r_{M}\right)+L_{N M}\left(r_{N M}-r_{M}\right)\right]+(1-\gamma)\left(\frac{1+\delta}{\delta+\tau}\right)\left[D_{M}\left(i_{M}-i_{O}\right)\right. \\
\left.+D_{N M}\left(i_{M}-i_{N M}\right)\right]
\end{aligned}
$$

\subsection{Constraints}

There are two distinct constraints that CBs face while striving to increase members' welfare to its maximum level. First among these constraints is the Balance Sheet Constraint. This requires that total assets and liabilities should balance.

\section{$L_{t}+I_{t}=D_{t}+R_{t}+U_{t}$}

The principal assets on the left-hand side, loans $(L t)$ and investments $(I t)$ equal the principal liabilities on the right-hand side - i.e., deposits $(D t)$, regular reserves $(R t)$, and undivided earnings $(U t)$. Assuming that the reserves and undivided earnings do not vary, the portfolio changes with new loans issued and is constrained by the following:

$$
\Delta L+\Delta I=\Delta D
$$

$$
\begin{aligned}
& \Delta L=L_{t+1}-L_{t} \\
& \Delta I=I_{t+1}-I_{t} \\
& \Delta D=D_{t+1}-D_{t} \\
& L_{t+1}=L_{t}(1-\theta)+L \\
& D_{t+1}=D_{t}(1-\tau)+D
\end{aligned}
$$

Note that T and $\theta$ capture the proportions of loans and deposits retired during each period. Since we need an expression in terms of $L$, we substitute ( 2 into ( 1 and obtain:The operating profits accruing to the CBs would be $\pi=R-C-T R$. Let $r$ ' and $i$ 'be the rates that reflect the weighted averages of the past loan and deposit periods and $T R$ is the transfer to reserves. We can write the profit term as:

$$
\begin{gathered}
\pi=\left[r^{\prime}\right](1-\rho)(1-\theta) L_{t}+(1-\rho)\left[L_{M} r_{M}+L_{N M} r_{N M}\right]+ \\
-\left[i^{\prime}\right](1-\rho)(1-\tau) D_{t}-(1-\rho)(1-\tau)\left[D_{M} i_{M}+D_{N M} i_{N M}\right]+ \\
+r_{O} I_{t+1}-\vartheta U_{t}-F C
\end{gathered}
$$

where $F C$ are the fixed costs - i.e., estate planning, investment counseling, etc., and $0 \leq \rho<1$ is the fraction transferred to regular reserves by legal requirements. For the sake of simplicity, we do not differentiate 
between member and non-member categories for past period loans. Introducing them, however, will not change the results qualitatively.

Since

$$
L_{t+1}+I_{t+1}=D_{t+1}+R_{t}+U_{t}
$$

the relationships in (2 upon substitution will yield:

$$
L_{t}(1-\theta)+L+I_{t+1}=D_{t}(1-\tau)+D+R_{t}+U_{t}
$$

From this we can obtain:

$$
I_{t+1}=D_{t}(1-\tau)+D+R_{t}+U_{t}-L_{t}(1-\theta)-L
$$

and by substituting ( 4 into (5, we get the profit constraint aligned with the cooperative's modus operandi, then set the profit to zero.

$$
\begin{gathered}
\pi=\left\{\left[r^{\prime}\right](1-\rho)-r_{O}\right\}(1-\theta) L_{t}+\left\{\left[(1-\rho)-r_{O}\right]\left[L_{M} r_{M}+L_{N M} r_{N M}\right]\right\}+ \\
-\left\{\left[i^{\prime}\right](1-\rho)+r_{O}\right\}(1-\tau) D_{t}-\left\{\left[(1-\rho)(1-\tau)+r_{O}\right]\left[D_{M} i_{M}+D_{N M} i_{N M}\right]\right\} \\
+R_{t} r_{O}+\left(r_{O}-\vartheta\right) U_{t}-F C=0
\end{gathered}
$$

\subsection{Determination of optimal interest rates}

Compared to credit unions, CBs face a more complex problem since they define four optimal interest rates. Their objective can be seen as maximizing the loan and deposit net gains for members, weighted by the preference parameters (borrower or depositor-oriented) given the member composition. While determining these optimal interest rates, $\mathrm{CBs}$ are constrained by both the balance sheet and operating statement, both included in Equation (5. We set the issue as a single-period problem, given that past decisions are introduced in the inherited balance sheet, but they do not affect the process of maximizing net gains. The CB's decision process only concerns the current rate decisions ${ }^{12}$.

The first order conditions of the constrained maximization problem are the following ${ }^{13}$ :

$$
\begin{aligned}
& \gamma \Lambda\left\{\frac{\partial L_{M}}{\partial r_{M}}\left(r_{O}-r_{M}\right)-\left(L_{M}+L_{N M}\right)\right\}-\lambda \frac{\partial \pi}{\partial r_{M}}=0 \\
& \gamma \Lambda\left\{\frac{\partial L_{N M}}{\partial r_{N M}}\left(r_{N M}-r_{M}\right)+L_{N M}\right\}-\lambda \frac{\partial \pi}{\partial r_{N M}}=0 \\
& (1-\gamma) \Phi\left\{\frac{\partial D_{M}}{\partial i_{M}}\left(i_{M}-i_{O}\right)+\left(D_{M}+D_{N M}\right)\right\}-\lambda \frac{\partial \pi}{\partial i_{M}}=0
\end{aligned}
$$

12 As Smith (1984) suggested, it is assumed that all parameters, exogenous market rates and functional relationships are known with certainty.

13 We do not demonstrate here that the bordered Hessian matrix is negative definite to show that the second-order conditions hold. 
$(1-\gamma) \Phi\left\{\frac{\partial D_{N M}}{\partial i_{N M}}\left(i_{M}-i_{N M}\right)-D_{N M}\right\}-\lambda \frac{\partial \pi}{\partial i_{N M}}=0$

$\pi=0$

where $\lambda$ is the Lagrangian multiplier. $\Lambda=\left(\frac{1+\delta}{\delta+\theta}\right), \Phi=\left(\frac{1+\delta}{\delta+\tau}\right)$, the partial effects of changes in interest rates on profits in the above expression, are as follows:

$$
\begin{aligned}
& \frac{\partial \pi}{\partial r_{M}}=\left\{\left[(1-\rho)-r_{O}\right]\left[\frac{\partial L_{M}}{\partial r_{M}} r_{M}+L_{M}\right]\right\}=\left\{\left[(1-\rho)-r_{O}\right]\left[L_{M}\left(1+\varepsilon_{r_{M}}^{L_{M}}\right)\right]\right\} \\
& \frac{\partial \pi}{\partial r_{N M}}=\left\{\left[(1-\rho)-r_{O}\right]\left[L_{N M}\left(1+\varepsilon_{r_{N M}}^{L_{N M}}\right)\right]\right\} \\
& \frac{\partial \pi}{\partial i_{M}}=\left\{\left[(1-\rho)(1-\tau)+r_{O}\right]\left[D_{M}\left(1+\varepsilon_{i_{M}}^{D_{M}}\right)\right]\right\} \\
& \frac{\partial \pi}{\partial i_{N M}}=\left\{\left[(1-\rho)(1-\tau)+r_{O}\right]\left[D_{N M}\left(1+\varepsilon_{i_{N M}}^{D_{N M}}\right)\right]\right\}
\end{aligned}
$$

The $\varepsilon$ terms in the above expressions denote the respective partial elasticities of loan and deposit demands with respect to different interest rates. Their interpretations are quite straightforward in this case.

The corresponding optimal interest rates are:

$$
\begin{aligned}
& r_{M}^{*}=r_{O}-\left[\frac{\frac{\lambda}{\gamma \Lambda L_{M}} \frac{\partial \pi}{\partial r_{M}}+\frac{1}{\alpha}}{\frac{\partial L_{M}}{\partial r_{M}} \frac{1}{L_{M}}}\right] \\
& r_{N M}^{*}=r_{M}+\left[\frac{\frac{\lambda}{\gamma \Lambda L} \frac{\partial \pi}{\partial r_{N M}}-(1-\alpha)}{\frac{\partial L_{N M}}{\partial r_{N M}} \frac{1}{L}}\right] \\
& i_{M}^{*}=i_{O}-\left[\frac{\frac{\lambda}{(1-\gamma) \Phi D_{M}} \frac{\partial \pi}{\partial i_{M}}+\frac{1}{\beta}}{\frac{\partial D_{M}}{\partial i_{M}} \frac{1}{D_{M}}}\right] \\
& i_{N M}^{*}=i_{M}+\left[\frac{\frac{\lambda}{(1-\gamma) \Phi D} \frac{\partial \pi}{\partial i_{N M}}-(1-\beta)}{\frac{\partial D_{N M}}{\partial i_{N M}} \frac{1}{D}}\right]
\end{aligned}
$$


As we mentioned earlier, $\alpha$ and $\beta$ denote the members' share of total loans and deposits. The $\gamma$ parameter defines the CB's preferential orientation towards either borrowers or depositors. The terms within the square brackets indicate the premiums that members and non-members receive and pay respectively over and above the relevant interest rates. For example, in the case of $r_{M}^{*}$, the term in the square brackets indicates the reduction in the member interest rate on loans, compared to the external rates offered by other commercial banks. Similarly, in the case of $r_{N M}^{*}$, the term inside the brackets indicates the premium that the non-members must pay over members' interest rates on loans. The same story holds for (additional) interest earned on deposits by the two groups. As in Smith (1984), it is possible to classify CBs according to their preference orientation as well.

$\begin{array}{llll}\text { Complete Borrower Preference } & (\gamma=1) & \frac{\partial \pi}{\partial r_{M} / \partial r_{N M}}>0 & \frac{\partial \pi}{\partial i_{M} / i_{N M}}=0 \\ & (\gamma=0.5) & \frac{\partial \pi}{\partial r_{M} / \partial r_{N M}}>0 & \frac{\partial \pi}{\partial i_{M} / i_{N M}}<0 \\ \text { Neutrality } & & \frac{\partial \pi}{\partial i_{M} / i_{N M}}<0\end{array}$

We can now summarize the factors that these optimal interest rates would depend on.

Remark 1. When there is a complete depositor-oriented preference, i.e., $\mathrm{Y}=0$,

1. Interest rates on loans:

- The optimal interest rate (on loans) for members depends on the share and size of total loans to members $\alpha$, external interest rates and the marginal effect of (member) interest rates on their loan demand functions.

- For non-members, the optimal interest rate depends on their share in total loans 1- $\alpha$, rates offered to members, total loan size and the marginal effect of rNM on their loan demand schedules.

- They are independent of the marginal effects of $\mathrm{rM}$ and $\mathrm{rNM}$ via the profit channel.

2. Interest rates on deposits:

- The optimal interest rate (for deposits) for members depends on the share and size of total deposits of members $\beta$, external interest rates and the marginal effect of (member) interest rates on their deposit demand functions.

- For non-members, the optimal interest rate depends on their share in total deposits $1-\beta$, rates offered to members, total deposit size and the marginal effect of iNM on their deposit demand schedules.

- They are dependent on the marginal effects of iM and iNM via the profit channel and these in turn depend on partial demand elasticities $\varepsilon_{i_{M}}^{D_{M}}, \varepsilon_{i_{N M}}^{D_{N M}}$.

3. The optimal rates also depend on the discount rates and share of loans (deposits) retired every period.

Remark 2. When there is an absolute borrower-orientated preference, i.e., $\mathrm{Y}=1$, the dependence relations are symmetric to the previous remark. 


\section{Interest rates on loans:}

- The optimal interest rate (on loans) for members depends on the share and size of total loans to members $\alpha$, external interest rates and the marginal effect of (member) interest rates on their loan demand functions.

- For non-members, the optimal interest rate depends on their share in total loans 1- $\alpha$, rates offered to members, total loan size and the marginal effect of rNM on their loan demand schedules.

- They are also dependent on the marginal effects of $\mathrm{rM}$ and $\mathrm{rNM}$ on profit and these in turn depend on partial demand elasticities $\varepsilon_{r_{M}}^{L_{M}}, \varepsilon_{r_{N M}}^{L_{N M}}$.

2. Interest rates on deposits:

- The optimal interest rate (for deposits) for members depends on the share and size of total loans to members $\beta$, external interest rates and the marginal effect of (member) interest rates on their deposit demand functions.

- For non-members, the optimal interest rate depends on their share in total deposits 1- $\beta$, rates offered to members, total deposit size and the marginal effect of iNM on their deposit demand schedules.

. They are independent of the marginal effects of iM and iNM via the profit channel.

3. The optimal rates also depend on the discount rates, as well as the share of loans (deposits) retired every period.

Remark 3. When the preference is not entirely borrower- or depositor-oriented, i.e., $0<\mathrm{\gamma}<1$

1. For members:

- The optimal interest rates for member loans (deposits) depends on external rates, the share $\alpha(\beta)$ and size of total loans (deposits) by members, as well as the marginal effect of member interest rates on their loan (deposit) demand functions.

- They depend on the discount rates and share of loans (deposits) retired every period.

- In addition, they also depend on the marginal influence of the loan (deposit) interest rate on profits, which in turn depends on the (partial) interest elasticity of demand for their loans, $\varepsilon_{r_{M}}^{L_{M}}$ (deposits: $\varepsilon_{i_{M}}^{D_{M}}$ ).

2. For non-members:

- The optimal interest rates on non-member loans (deposits) depend on the share in total loans, 1- $\alpha$ $(1-\beta)$ rates offered to members, the total loan (deposit) size, as well as the marginal effect of iNM on their loan (deposit) demand schedules.

. They depend on the discount rates and share of loans (deposits) retired every period.

- In addition, they also depend on the marginal influence of the loan (deposit) interest rate on profits, which in turn depends on the (partial) interest elasticity of demand for their loans, $\varepsilon_{r_{N M}}^{L_{N M}}$ (deposits: $\left.\varepsilon_{i_{N M}}^{D_{N M}}\right)$. 


\section{Discussion and extensions}

We considered a single-period decision-making scenario in which CBs decide optimal interest rates for loans and deposits for both members and non-members. A relatively general model of $\mathrm{CBs}$ with nonmember customers and with different overall orientations (depositor- or borrower-orientation) has been proposed and thus we derived the optimal interest rates within this framework. According to our results, in order to be both competitive in the market and faithful to their cooperative aim, CB interest rate settings should include a premium determined by taking into account the relevant partial elasticities for each type of customer - non-members (borrowers or depositors) and members (borrowers or depositors). The model developed here is a generalized framework that includes credit unions as a particular type of CBs for which both (1- $\alpha)$ and $(1-\beta)$ are equal to zero.

The baseline model outlined above can be extended by introducing further complexities. The model, as we have outlined so far, has no uncertainty - i.e., no probabilities regarding default have been introduced. This can be modified to introduce risk factors associated with lending to different types of customers. This means that we have to amend the revenues and replace them with expected revenues. The risk factors associated with non-members and the resulting optimal interest rates would give a more complete description. In this exercise, we have considered how optimal interest rates can be derived for a given loan size $(L)$, although we have not emphasized it throughout. The total loans are shared between members and non-members. The resulting shares $\alpha,(1-\alpha)$ in the case of loans, $\beta,(1-\beta)$ in the case of deposits, are endogenous; in turn, they depend on member and non-member demand schedules. Alternatively, we can let the total amount of the loan vary as well. From the expressions for optimal interest rates, we can see how they change for members and non-members, with respect to a change in member orientation across the spectrum (from being borrower-oriented to depositor-oriented). It is worth noting that $\alpha$ and $\beta$ enter into the expressions for optimal rates, indicating the role played by the ratio between the outstanding loans to members to non-members, along with the preference-orientation parameter $Y$ and the partial elasticity parameters $(\varepsilon)$.

Within this framework, we do not address dynamic or long-term motivations to keep non-members appeased. Here, members as a group have opposing aims and no explicit cooperative behavior with nonmembers, although they gain from non-members, who bring in more revenues. Members are seen as trying to maximize their gains in the current period. However, this may not be the case when repeated interactions are involved. In fact, the member and non-member groups need to "cooperate" in order to get the best possible outcome for the community of customers as a whole. This means there is a scope for negotiating each group's gains, with a long-term perspective in mind. The same holds for depositors and borrowers, especially when the same customer can play both roles. This cooperative aspect can probably be better understood in alternative frameworks that blend cooperative and competitive behavior (see Ray, 2007). For instance, it might be instructive to study the mechanics or processes by which groups reach agreements and the possibilities of coalition formation from a game-theoretic perspective. Alternatively, in the presence of repeated interactions, identifying strategies that different competing groups (such as members and non-members) employ in the absence of non-binding agreements between them may also be useful. This might shed light on how mutually beneficial outcomes are eventually reached for both groups, where there is scope for symbiotic relationships between them. Another extension includes exploring alternative frameworks to understand the role of non-members as well as the dynamic stability of non-member shares. 


\section{References}

Alexopoulos, Y., Catturani, I. and Goglio, S. (2013). Searching for a Model of Governance in Cooperative Banking. In Brazda, J., Dellinger, M. and Rößl, D. (eds.). Genossenschaften im Fokus einer neuen Wirtschaftspolitik - Bericht der XVII. Vienna 2012 Internationalen Genossenschaftswissenschaftlichen Tagung (IGT) (International Conference on Cooperative Studies). Berlin: LIT Verlag.

Berger, A.N., Demsetz, R.S. and Strahan, P.E. (1999). The Consolidation of the Financial Services Industry: Causes, Consequences, and Implications for the Future. Journal of Banking and Finance. 23: 135194. http://dx.doi.org/10.1016/S0378-4266(98)00125-3

Berthoud, R. and Hinton, T. (1989). Credit unions in the United Kingdom. London: Policy Studies Institute.

Bonaccorsi di Patti, E. and Gobbi, G. (2001). The changing structure of local credit markets: Are small business special?. Journal of Banking and Finance, 25: 2209-2237. http://dx.doi.org/10.1016/ S0378-4266(01)00191-1

Croteau, J.T. (1963). The Economics of Credit Union. Detroit: Wayne State University Press.

DeYoung, R., Goldberg, L.G. and White, L.J. (1999). Youth Adolescence and Maturity at Banks: Credit Availability to Small Business in an era of Bank Consolidation. Journal of Banking and Finance, 23: 463-492. http://dx.doi.org/10.1016/S0378-4266(98)00086-7

European Association of Co-operative Banks (2013). Official web site: www.eacb.coop

Emmons, W.R. and Mueller W. (1998). Conflict of Interest between Borrowers and Lenders in Credit Co-operatives: The Case of German Co-operative Banks. Federal Reserve Bank of St. Louis working paper.

Emmons, W.R. and Schimd F.A. (2002). Pricing and Dividend Policies in Open Credit Cooperatives. Journal of Institutional and Theoretical Economics, 158: 234-255. http://dx.doi. org/10.1628/0932456022975439

Fici, A. (2010). Italian Co-operative Law Reform and Co-operative Principles, Euricse Working Papers, 2 | 2009. Available online at: http://papers.ssrn.com/sol3/papers.cfm?abstract_id=1615344 [Accessed: 3 February 2014].

Goglio, S. (2009). Local credit and territorial development: General aspects and the Italian experience. In Leonardi A. (ed.) Post-war Economic Recovery and Development in Peripheral European Areas. Bologna: Il Mulino.

Hart, O. and Moore J. (1998). Cooperative vs. Outside Ownership. NBER Working Paper Series, 6421 52.

Muqtadir M. (2013). Introduction to Credit Union Statistics. Bank of England. Available online at: www. bankofengland.co.uk/statistics/Documents/ms/articles/art1 jul13.pdf. [Accessed: 3 February 2014].

Oxford Dictionary of Economics (2009). Available online at: www.oxfordreference.com [Accessed: 3 February 2014].

Pantaleoni, M. (1898). Esame critico dei principii teorici della cooperazione. Giornale degli Economisti, XVI marzo-aprile-maggio.

Pantaleoni, M. (1924). Un esempio di falsa cooperazione. Reprinted in Erotemi di economia (1964) II. Padova: Cedam.

Petersen, M.A. and Rajan R.G. (1995). The effect of credit market competition on lending relationships. Quarterly Journal of Economics, 110: 407-443. http://dx.doi.org/10.2307/2118445

Ray, D. (2007). A Game theoretic Perspective on Coalition Formation. Oxford: Oxford University Press. http://dx.doi.org/10.1093/acprof:oso/9780199207954.001.0001 
Smith, D.J. (1984). A Theoretical Framework for the Analysis of Credit Union Decision Making. The Journal of Finance, 39 (4): 1115-1168. http://dx.doi.org/10.1111/j.1540-6261.1984.tb03899.x

Smith, D.J. (1988). Credit Union Rate and Earnings Retention Decisions under Uncertainty and Taxation. Journal of Money, Credit and Banking, 20 (1): 119-131. http://dx.doi.org/10.2307/1992670

Smith, D.J., Cargill, T.F. and Meyer, R.A. (1981). Credit Unions: An Economic Theory of Credit Union. The Journal of Finance, 368 (2): 519-528. http://dx.doi.org/10.2307/1991817 http://dx.doi.org/10.2307/1991819

Taylor, R.A. (1977). Credit Unions and Economic Efficiency. Rivista Internazionale di Scienze Economiche e Commerciali, 24: 239-247.

Ward, A.M. and McKillop, D. (1997). The Relationship Between Credit Unions Objects and Cooperative Philosophies. Credit Union Research Forum Working Paper, 1. 


\section{IEOD \\ ENTREPRENEURIAL AND \\ ORGANIZATIONAL \\ DIVERSITY}

www.jeodonline.com 